\title{
An unusual fossil larva, the ontogeny of achelatan lobsters, and the evolution of metamorphosis
}

\author{
JOACHIM T. HAUG \& CAROLIN HAUG
}

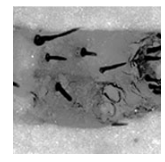

\begin{abstract}
Metamorphosis is a striking feature in the development of an animal. For arthropods, metamorphosis is usually understood as a rapid morphological change, which occurs within one or two moults. We describe here two conspecific fossil larvae of an achelatan lobster from the Solnhofen Lithographic Limestones (Upper Jurassic, southern Germany). These phyllosoma-like larvae represent successive instars. Both have a combination of characters specific for phyllosoma larvae and those typical for post-phyllosoma instars. This find indicates that the developmental pattern of this achelatan species was more gradual or "less metamorphic" than in all other achelatans known, and probably represents the plesiomorphic condition. Obviously, heterochrony played an important role in the evolution of metamorphosis in Achelata. Developmental data from other fossil arthropods, e.g., stomatopod crustaceans or pterygote insects, also point to a more gradual ontogenetic pattern in the ancestors of these lineages, which show a "real" metamorphosis today. The evolution of metamorphosis is linked to selective pressure on early developmental stages, resulting in morphological disparity between pre- and post-metamorphic stages, and a condensation of the ontogenetic pattern, leading to a more rapid morphological change. The influence of both factors can be better evaluated if fossil information is taken into account. $•$ Key words: metamorphosis, Palaeo-Evo-Devo, larval biology, Decapoda, Eucrustacea.
\end{abstract}

HAUG, J.T. \& HAUG, C. 2013. An unusual fossil larva, the ontogeny of achelatan lobsters, and the evolution of metamorphosis. Bulletin of Geosciences 88(1), 195-206 (3 figures). Czech Geological Survey, Prague. ISSN 1214-1119. Manuscript received July 4, 2012; accepted in revised form October 6, 2012; published online December 5, 2012; issued December 6, 2012.

Joachim T. Haug (corresponding author) \& Carolin Haug, Zoological Institute and Museum, Department of Cytology and Evolutionary Biology, University of Greifswald, Soldmannstraße 23, 17487 Greifswald, Germany; joachim.haug@palaeo-evo-devo.info,joachim.haug@uni-greifswald.de

\begin{abstract}
Metamorphosis describes a rapid change of the morphology during ontogeny. What this exactly means, or more exactly to which ontogenetic sequences the term metamorphosis should be applied, differs from author to author (see discussion in Williamson 1982). The differences in applying the term metamorphosis concern both the amount and the rapidness of change. The amount of change means the differences in morphology between the last developmental stage before and the first stage after metamorphosis, while the rapidness of change refers to how fast this entire process happens. Yet, there are some cases in which it is easier to decide than in others, whether a developmental change is a metamorphosis or not. Among arthropods usually those taxa are considered to undergo metamorphosis, which change their morphology drastically within a single or at most two moults, with this characterizing the degree of rapidness of this change. Practically, this means that the animal creeping out of the old cuticle shows only little resemblance to its old "skin".
\end{abstract}

A well-known example are holometabolous insects. Here the larva, for example, a caterpillar, moults into the pupa (in fact another type of larva; see Barnes et al. 1993), which moults into the adult, in this case a butterfly. While holometabolous insects are probably the best-known example for metamorphosis within arthropods, also among crustaceans drastic changes of morphology within no more than two moults are not rare. In Branchiopoda, for example, Lynceus brachyurus Müller, 1776 moults from the last metanauplius larva, which is covered dorsally by a univalved shield and effectively ventrally by an oversized labrum, technically being "bivalved" dorso-ventrally, into the juvenile with its body enclosed into the now real bivalved shield with left and right valves (Olesen 2005). Another example are barnacles and their relatives, which undergo a drastic change from their last metanauplius larva to the cypris larva and again to the sessile juvenile or to a host-dependent parasite (e.g., Walossek et al. 1996, Høeg et al. 2004, Briggs et al. 2005, Kolbasov et al. 2008). 
Also among the well-known reptantian decapod crustaceans, crabs undergo a drastic morphological change from their free-swimming larval stages, zoea and megalopa, to mainly benthic adults. The most drastic metamorphosis within reptantian crustaceans has been reported from Achelata, a taxon comprising slipper lobsters, rock lobsters and spiny lobsters. This drastic change occurs at the moult from the last zoea-equivalent stage to the megalopa-equivalent stage (both sensu Williamson 1969). The zoea equivalent in Achelata is termed phyllosoma larva. These larvae, as the name suggests, remind distantly of leaves. They are paper-thin, flat, and appear very translucent. Yet, they can grow to a size of several centimeters (e.g., Johnson 1951). The area between the insertions of the second antennae and the mouth parts is very elongated and forms dorsally a translucent so-called head shield (although not covering the entire head). The ventral area of the thorax is relatively broad, which lets the thoracic appendages insert functionally laterally. These biramous appendages appear long and fragile, are very thin and also translucent. The distal ends of the long pereiopods are specialized for grabbing small prey items; phyllosoma larvae are predators (Jeffs 2007, Saunders et al. 2012). The "shrimp tail", i.e., the pleon of these larvae, is tiny and its appendages develop relatively late within the ontogenetic sequence. An achelatan lobster can undergo about ten successive phyllosoma larval stages and will then moult into a puerulus or nisto, largely resembling the adult, yet still representing larvae due to their pelagic lifestyle (Marinovic et al. 1994, Mikami \& Greenwood 1997, Webber \& Booth 2001, Inoue et al. 2004; discussion of the last stage being a larva see, e.g., in Felder et al. 1985).

Walossek (1993) concluded, based on studies of fossil representatives of Eucrustacea from the Cambrian, that the ground pattern of Eucrustacea is characterized by a relatively gradual mode of development and that developmental jumps within this series, such as in decapods, are derived features. The drastic morphological changes during the ontogeny of achelatan lobsters can be considered as being even more derived.

Fossils in general have the potential of preserving character states that are no longer represented in any extant taxon (e.g., Donoghue et al. 1989, Waloszek 2003, Rust 2006, Edgecombe 2010). This is also true for developmental patterns (e.g., Haug, J.T. et al. 2010a). It is therefore worth considering that among the fossil representatives of Achelata there could be at least one that exhibits a more gradual developmental pattern than all extant representatives of the group. Astonishingly, phyllosoma larvae are quite well-represented in the fossil record despite their fragile nature. There are thousands of specimens of phyllosoma larvae in the deposits of the Solnhofen Lithographic Limestones (Upper Jurassic, southern Germany). Until now five different types of phyllosoma larvae have been reported from there (Polz 1972, 1973, 1984, 1995;
Haug J.T. et al. 2009, 2011). Two additional forms have been reported from the related deposits from the Upper Cretaceous of Lebanon (Pasini \& Garassino 2009, Haug, J.T. et al. 2011). Finally, exceptionally preserved eyes from the Cretaceous of Brazil have been interpreted as representing the remains of phyllosoma larvae (Tanaka et al. 2009). Until now, all of these numerous examples of fossil phyllosoma larvae resemble the principal morphology of extant phyllosoma larvae (but see discussion for details).

We report here two specimens from the Solnhofen Lithographic Limestones that possess a mixture of phyllosoma- and post-phyllosoma-specific characters. It is discussed, whether these specimens hint to a more gradual development in the early evolutionary lineage towards the modern achelatan lobsters, and how these new findings add to our general view on the evolution of metamorphosis.

\section{Material and methods}

Two specimens were the basis for the present paper, handed over to us by Hermann Polz, Geisenheim, one of the most important non-professional scientists for the lithographic limestones of southern Germany. The specimens were found near Wegscheid/Eichstätt ( $c a 150$ million years old) and are now part of the collection of the Museum für Naturkunde Stuttgart (SMNS 67716/1 and 67716/2).

Both specimens were documented under a Zeiss Axioskop 2 fluorescence microscope with a $2.5 \times$ objective while exposed to green light (546 nm excitation wavelength) using the autofluorescence capacities of the specimens (Haug, C. et al. 2009a). Details of SMNS 67716/1 were additionally documented with a $5 \times$ objective under the same settings. For high-resolution images composite imaging was applied (Haug, J.T. et al. 2008, Haug, C. et al. 2009a); the processing was performed with the computer software CombineZM, CombineZP, Adobe Photoshop CS3 and Microsoft Image Composite Editor.

SMNS 67716/2 is present as part and counterpart, images of both were placed in one image as separate layers. The upper layer was flipped horizontally and alligned with the lower one according to significant landmark structures. While we used the magic wand tool to remove the background from the upper layer in earlier approaches (Haug, C. et al. 2009a), this time we exported both layers as separate images and imported these as a stack in ImageJ. Both frames of the stack were then Z-projected with a maximum intensity projection.

For comparison further extant and fossil specimens were documented. A permanent mount of an extant phyllosoma larva of a spiny lobster from the Invertebrate Zoology collection of the Yale Peabody Museum of Natural History, New Haven (YPM IZ 055932) was documented under transmitted white light/brightfield conditions on a Leica DM 2500 P microscope with a ScopeTek 
DCM 510 ocular camera. Images of an adult slipper lobster from the same collection [Scyllarides nodifer (Stimpson, 1866), YPM IZ 035855] were recorded under reflected polarized light with a Canon EOS Rebel T3i camera with an EF-S 18-55 mm lens, while the specimen was submersed in alcohol. Two extant stomatopod larvae from the collections of the Forschungsinstitut Senckenberg, Frankfurt/Main, were documented in alcohol under reflected polarized light, one (SMF Me5-118KuP) with a Canon EOS 450D camera with a Canon Macro Photo Lens MP-E $65 \mathrm{~mm}$, the other one (SMF Me5-194Ku) under an Axioskop microscope with a ScopeTek DCM 510 ocular camera. Images of two fossil insect nymphs from the Mazon Creek formation (Carboniferous, North America) housed in the Invertebrate Paleontology collection of the Royal Ontario Museum, Toronto (ROM 45546, ROM 47971) were recorded under reflected polarized light with a Canon EOS Rebel T3i camera with an MP-E 65mm lens. Image stitching or composite imaging (when stacks were recorded) was applied (see above). Color and contrast optimization (histogram, saturation, "mask unsharp" filter) of all specimens was performed either in Adobe Photoshop CS3 or in Gimp 2.6. Furthermore, 3D models of two different ontogenetic stages of the fossil mantis shrimp Spinosculda ehrlichi Haug, Haug \& Waloszek, 2009 from the Solnhofen Lithographic Limestones were made in Blender, based on information from Haug, C. et al. (2009b) and Haug, J.T. et al. (2010b).

\section{Results}

Both specimens resemble each other and are considered to be conspecific. Yet, they differ in size and also in certain morphological features and are, therefore, interpreted to represent two successive instars; the larger specimen is about 14-17\% larger than the smaller specimen, which is within the range of growth within a single moult in crustaceans ( $c f$. Kutschera et al. 2012). As the smaller specimen (SMNS 67716/1) is preserved with more detail, this earlier instar is described first, then differences in the morphology of the second specimen (SMNS 67716/2) are highlighted.

\section{Description of the earlier instar (SMNS 67716/1; Fig. 1)}

Specimen SMNS 67716/1 is interpreted as representing an immature developmental stage of an achelatan lobster (Fig. 1). The body proper is only incompletely known due to preservation. A small sclerotic plate represents a sternal structure, which is hexagonal in shape, more elongated towards the anterior, but stouter posteriorly (Fig. 1A). This plate is surrounded by remains of in total eight pairs of appendages. These can be identified as antennulae, antennae, the third maxillipeds and five pairs of pereiopods, with the pereiopods $1-5$ directly adjacent to the sternal plate (Fig. 1A).

One of the antennulae is represented by remains of two flagella, which are preserved close to each other distally, one with three annuli, the other one with two annuli (Fig. 1A). More proximally five additional annuli are present, but it remains unclear to which of the distal flagellar parts they belong. A further proximal fragment most likely represents a piece of the peduncle of this antennula.

The antenna is also just known from discontinuous fragments (Fig. 1A). A fragment of the peduncle is preserved that seems to represent a more or less complete element, as well as a multi-annulated more distal element, which is incomplete. This multi-annulated part comprises three closely aligned pieces of one, four, and five annuli respectively. The three pieces are each about the length of one annulus apart from each other, therefore, they represent a part of the distal area of the antenna of about twelve annuli. Based on the distance to the peduncle elements, the antenna is interpreted to have possessed more than 30 annuli.

The succeeding appendages, mandible, maxillula, (second) maxilla, maxilliped 1 and 2 are not preserved. The next known appendage is the maxilliped 3 . The most proximal element of the maxilliped 3 appears to be jointed to the body anterior to the sternal plate (Fig. 1A). The appendage consists of six elements, coxa, basipod and four endopodal elements. An exopod could not be found, but it remains unclear if this is due to preservation or if it was really absent. Basipod and third endopodal element are not preserved and are only recognizable through the presence of the adjacent elements. The most proximal element, coxa, is only faintly preserved, but appears to be cone-shaped. The basipod was supposedly slightly longer than the coxa, and the first endopodal element is again longer than the basipod. Endopodal element two is shorter than one, about two third of the length of the latter, and endopodal element three was probably shorter than two. At least endopodal elements one and two, probably also three and the basipod, are tube-shaped. Endopodal element four, the dactylus is a little hook or nail, about half the length of endopodal element two.

Pereiopods $1-5$ are very similar in their morphology, mainly differing in their length (Fig. 1A). Pereiopods 1-3 are of about the same length and slightly longer than the subsequent two pairs, which are again of similar length. Furthermore, the thickness of the pereiopods decreases from anterior to posterior, with pereiopod 1 being the thickest. All pereiopods consist of coxa, basipod, four endopodal elements and an exopod. Shape and length of the coxa are hardly discernible on the specimen, but the coxa was probably significantly longer than the basipod, at least twice as long as the latter. The basipod is ring-shaped and about twice as wide as long and gives rise to the 
endopod (distally) and exopod (latero-distally). The endopods appear relatively robust. Endopodal elements 1-3 are more or less tube-shaped and about the same width as the basipod. The distal end of endopodal element three is slightly narrower than the rest of this element, possibly indicating the former presence of a separate element. Endopodal element one is about 2.5 times the length of the basipod, element two is about two third of the length of element one. The longest endopodal element is element three, which is about twice as long as element two. Endopodal element four, the dactylus, is a hook or nail, with its base about half as wide as element three. It is about half as long as endopodal element one.

The exopod has a cone-shaped base which is slightly more than two times the length of the basipod, but a bit narrower at its maximum width. From the distal end of the exopodal cone a flagellum arises, which is at least as long as the cone (Fig. 1D).

The entire endopods of pereiopods 1-5 are covered with setae, which just became obvious under the fluorescence microscope (Fig. 1A-C). Also the insertion areas of the setae are apparent, so that it is clear where setae have been present in the living animal even if it lost them later on. The setae on most parts of the endopods seem to be randomly distributed. Just near the distal end of endopodal element three, the setae form a ring at least partly surrounding the distal hook (Fig. 1B, C).

\section{Differences in the morphology of the later instar (SMNS 67716/2; Fig. 2)}

The most obvious difference to specimen SMNS 67716/1, besides the size difference, is the lack of a sternal sclerotic plate (Fig. 2A), but this might be taphonomically induced. In general, the virtual combination of part (Fig. 2B) and counterpart (Fig. 2C) of this specimen resulted in a fairly complete morphology of most of the larger appendages (Fig. 2D).

A further difference to the earlier instar is that maxilliped 3 seems to be stronger sclerotised in the later instar, possibly a developmental effect (Fig. 2A). The main difference is the lack of exopods on all five pairs of pereiopods in contrast to their presence in the earlier instar, which is interpreted as a true ontogenetic effect as all other parts of these appendages are present and well preserved (Fig. 2A).

\section{Discussion}

\section{Developmental pattern of the new specimens}

The here described specimens represent two unusual successive developmental stages of a reptantian decapod. They can be easily identified as representatives of Achelata, based on the absence of chelae and on the presence of only six articulated elements (coxa, basipod, endopod) on the pereiopods, and also on the absence of a well-developed scaphocerite (exopod of the antenna). All known representatives of Achelata undergo three post-embryonic developmental phases:

1) the phyllosoma phase (zoea equivalent sensu Williamson 1969),

2) the megalopa phase (sensu Williamson 1969, usually only one instar), in Achelata termed nisto or puerulus, and

3) the post-larval phase in its strict sense (but see, e.g., Felder et al. 1985), comprising the juvenile and the adult sub-phases.

Especially the phyllosoma phase is well-discernible from the later stages. Therefore, it is not surprising that the moult from the last phyllosoma stage to the puerulus stage is termed metamorphosis. The phyllosoma phase (Fig. 3A) can be identified so easily due to the peculiar structure of the body, differing in head, thorax and pleon morphology from that of the adult (Fig. 3B), as well as in the arrangement and composition of the thoracic limbs, which are equipped with natatory exopods and thin and elongate endopods. Additionally, some of the thoracic limbs are equipped with a special raptorial sub-chela, while the adults have achelate appendages (Achelata!).

The here described specimens appear to possess a mixture of some phyllosoma-specific features and other features that characterize the post-phyllosoma phase in achelatan lobsters (puerulus or juvenile characters). Among the typical phyllosoma characters is the thin phyllosoma-type "head shield", which is not preserved due to its weakly sclerotised cuticle. Its outline is indicated by the positions of pereiopods and rather far anterior inserting antennae (yet not as far anterior as in phyllosomes in the strict sense, Fig. 3A). Furthermore, the semi-circular posture of the pereiopods and the occurrence of pereiopodal exopods on the smaller specimen are phyllosoma characters. Of typical post-phyllosoma appearance are especially the pereiopodal endopods that are not thin and elongated in appearance, but robust and massive. Also the rather stout dactylus and its lack of spines (just like on the next proximal element, the propodus) show post-phyllosoma morphology. The absence of pereiopodal exopods in the larger specimen is not considered to be an artifact, but to reflect the actual morphology, thus also representing a post-phyllosoma character. The only unusual characters of this specimen are again the circular arrangement of the pereiopods and the obviously weakly sclerotised cuticle of the shield. Other characters of the specimen are clearly post-phyllosoma (juvenile) specific. Functionally comparable larvae with a phyllosoma-like body, but "normal", rather stout appendages can be found among parasitic gnathiid isopods, but have, of course, evolved convergently. 


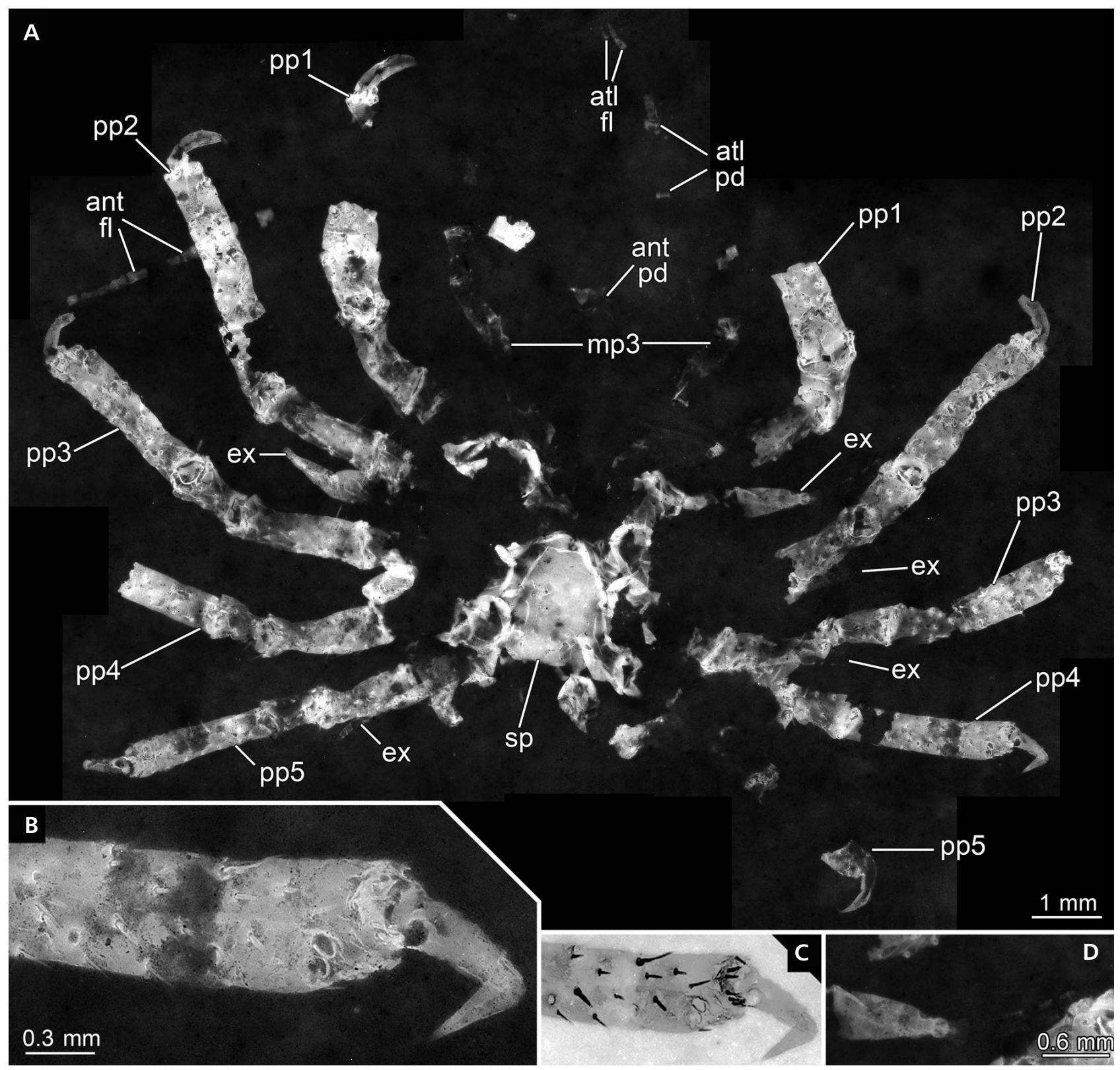

Figure 1. Smaller instar of phyllosoma-like achelatan larva (SMNS 67716/1). A - overview. $\bullet$ B - detail of left fourth pereiopod (right side in A). - C - inverted image of B, setae enhanced as dark structures. - D - exopod of left first pereiopod. Abbreviations: ant - antenna; atl - antennula; ex - exopod; fl - flagellum; mp3 - maxilliped 3; pd - peduncle; pp1-5 - pereiopods 1-5; sp - sclerotic plate.

There are two other examples of fossil achelatans with a morphological "mixture" of phyllosoma and puerulus or juvenile characters, possibly representing so-called early megalopae (Polz 1995, Haug, J.T. et al. 2009). Originally, Polz (1995) had interpreted this supposed early megalopa as "caught in the act" of moulting from the last phyllosoma stage into the puerulus. If an early megalopa occurs, the megalopa phase has to be considered to comprise two stages instead of one. But also in this case the metamorphosis from the phyllosoma to the puerulus still occurs within just two moults (from last phyllosoma stage to the early megalopa and then to the puerulus), and with this the principle criterion for metamorphosis would still be fulfilled.

The here described specimens appear to represent an even more gradual developmental pattern than the one including a single intermediate stage like an early megalopa. If we assume that the last stage before the smaller of the two specimens was a phyllosoma in the strict sense and that the next stage after that represented by the larger specimen was a true puerulus, the transformation from the phyllosoma to the puerulus would have taken three moults (from a terminological point of view the stages could also be 
termed puerulus for the small specimen and first juvenile for the larger one, both retaining larval features). Based on the very gradual change from the smaller to the larger specimen, it is plausible to assume that the development included even more moults.

Alternatively, the developmental pattern indicated by the two here described specimens could also mean that no phyllosoma phase in the strict sense had been present yet. This assumption leads to a scenario in which the highly specialized morphology of modern phyllosomata developed in two evolutionary steps. First, the thin body evolved, but not yet the long and slender limbs, resulting in the morphotype represented by the here described fossils. In a second step, the typical phyllosoma limbs evolved. We will need to reconstruct a more complete ontogenetic sequence for this form before we can decide which of the two possible evolutionary scenarios happened more likely.

\section{Ancestral developmental pattern of Achelata}

In both possible interpretations, the developmental pattern as indicated by the here described fossils is more gradual than that of any other representative of Achelata. It most likely represents the plesiomorphic developmental pattern for Achelata. The species can, therefore, be hypothesized to represent the sister group to all remaining achelatans, which all have a metamorphic moult from phyllosoma to puerulus (nisto for scyllarids).

The find indicates that also the timing of development of different structures was originally different, at least if a phyllosoma in the strict sense occurred before the earlier instar of the here described specimens. The softness of the shield and most parts of the body appear to be coupled with the elongated and fragile nature of the limbs in modern forms. Yet, the fossils demonstrate that this coupling is most likely derived. Originally, here meaning plesiomorphically, the limbs developed "faster" than the body, which longer retained its larval morphology. This would be another case of heterochrony, having been suggested to play an important role in the evolution of Achelata before (Haug, J.T. et al. 2009). The difficulties in applying the concepts of heterochrony here result from a lack of a clear phylogenetic background ( $c f$. Haug, J.T. et al. 2010a). We first need to clarify the systematic affinities of the here described form before we can finally conclude the polarity of the heterochronic change.

\section{Closer systematic affinities}

The question remains whether the here described immature fossils can be ascribed to any of the described co-occurring achelatan lobsters. The limbs especially show a certain resemblance to the limbs of Cancrinos claviger Münster, 1839. Yet, the juvenile development and the adult morphology of C. claviger indicate a sister-group relationship of this species to Scyllaridae sensu stricto, both united in Scyllaridae sensu lato (Haug, J.T. et al. 2009). Additionally, the so-called larva $\mathrm{C}$, a phyllosoma in the strict sense from the same locality, has also been suggested to represent the larval form of C. claviger (Polz 1996).

Based on the present material the possible conspecifity of the here described specimens and Cancrinos claviger can neither be verified, nor completely rejected. If these specimens are representatives of $C$. claviger, this would have several severe consequences. First, we would lack a candidate for being the adult of larva C. Second, the phylogenetic position of $C$. claviger would need to be re-evaluated, causing character conflicts concerning the antennal morphology, which is well explained by the existing phylogeny (Haug, J.T. et al. 2009). Alternatively, the developmental pattern described here could be autapomorphic (in this scenario) for C. claviger, or the more drastic metamorphic change must have evolved independently in Scyllaridae sensu stricto and in Palinuridae.

All these scenarios are unsatisfactory. To solve this problem, a thorough reinvestigation of the fossil material of the achelatans from the Solnhofen Lithographic Limestones is planned. This reinvestigation would include testing other hypotheses, such as the possibility raised by Polz (1995) that certain supposed species indeed represent pueruli of other described species.

\section{The evolution of metamorphosis}

Metamorphosis has been studied intensively in certain taxa (e.g., Drosophila melanogaster Meigen, 1830; Bainbridge \& Bownes 1981), and also complex theoretical models for the selective pressures for its timing have been proposed (e.g., Rowe \& Ludwig 1991). Yet, it has been stated that metamorphosis, as important phase of the life cycle, has in fact been poorly studied for most metazoans (Pechenik 2006). In the following, we concentrate on the evolution of metamorphosis in arthropods.

Therefore, gaining more knowledge on the evolutionary mechanisms that lead to metamorphosis is an important task. Understanding the emergence of metamorphosis as a strict evolutionary process is one of the major points to emphasize. The idea of "larval transfer" put forward by Williamson (1988; further developed, e.g., in Williamson 2006,2012 ) is not seen as an appropriate explanation. He assumed that distantly related taxa interbreed and the offspring then should change from the one form to the other during ontogeny. Recently, he offered a test for his idea that, for example, lepidopteran caterpillars and similar larvae of various holometabolous insects originated from 

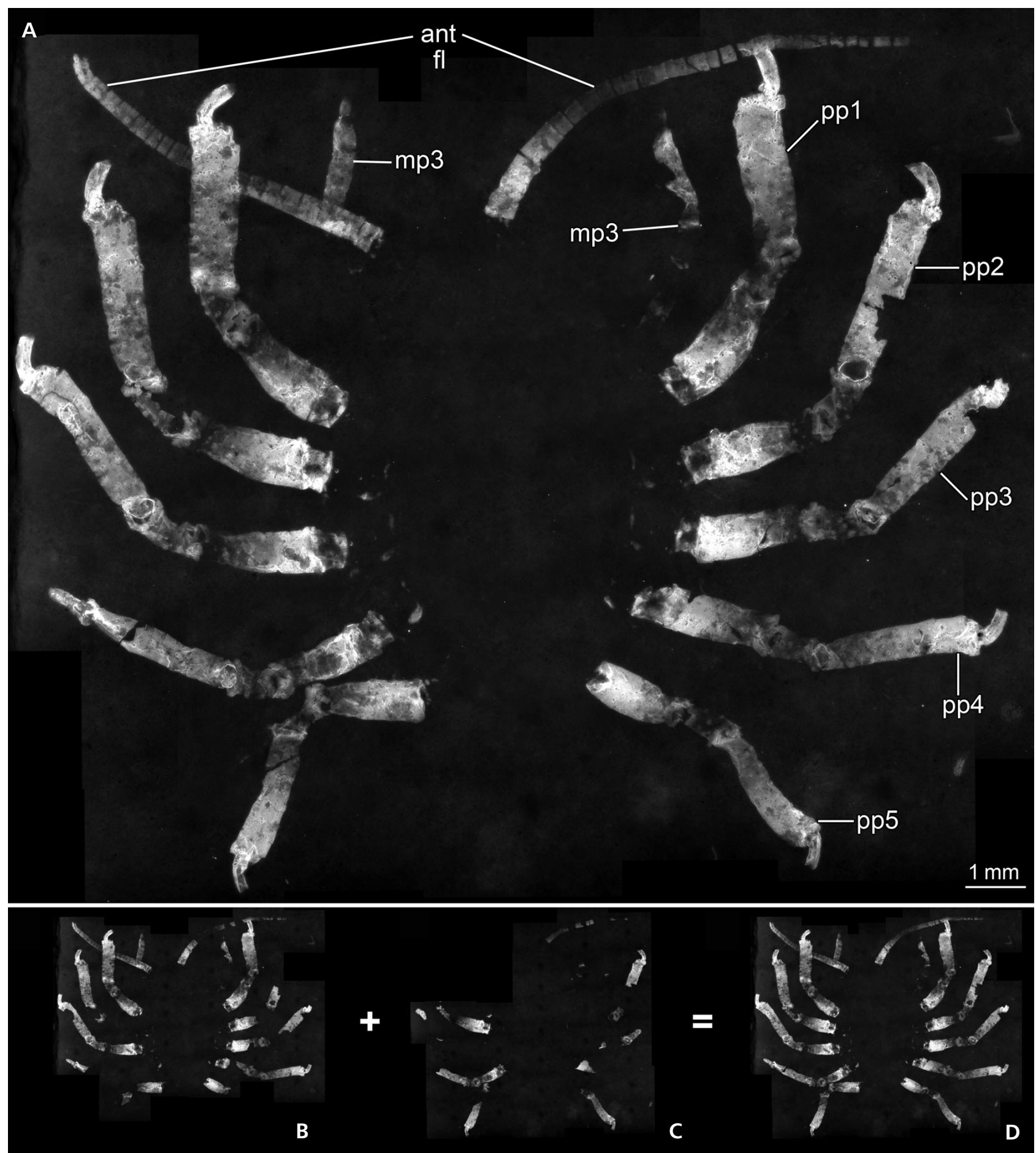

Figure 2. Larger instar of phyllosoma-like achelatan larva (SMNS 67716/2). A - compound image of part and counterpart. $\bullet$ B - part. $\bullet$ C - counterpart, flipped horizontally. $\bullet \mathrm{D}-$ minimum intensity projection of $\mathrm{B}+\mathrm{C}$. Abbreviations as in Fig. 1.

crossbreeding with onychophorans (Williamson 2009). However, under repeated tests of other researchers all his proposed tests failed, there remains no single support for this theory (e.g., Hart \& Grosberg 2009, Willis \& Cox-Foster 2010). The theory of larval transfer has very recently been revoked by Ferrari et al. (2011), yet with no clear argumentative support. Our findings also do not support the concept of larval transfer. In the following, we point out that the evolution of metamorphosis can be understood in many cases as a result of natural selection, and focus on 
two supposed mechanisms that can be supported by data from the fossil record.

Although we cannot reconstruct the entire ontogeny of the achelatan species from the here described specimens, the parts that we know give us important clues about the evolution of metamorphosis. We proposed two alternative interpretations how the indicated series could have evolved. Both interpretations lead to the conclusion that the here described developmental pattern comprises less drastic changes than in other representatives of Achelata. This is, in fact, the best we can state, that an ontogenetic pattern appears "more metamorphic" or "less metamorphic" than that of its ancestor (for the ancestor problem see Haug J.T. et al. 2010a). We can currently not provide a strict measurement for the degree of morphological differentiation, we can only recognize relative differences.

Our recognition of the developmental pattern represented by the here described fossils as "less metamorphic" is simply coupled to the criteria of the term metamorphosis. The two criteria for metamorphosis are 1) a pronounced morphological disparity between two successive ontogenetic phases and 2) a rapid change from the one to the other morphology. Thus, there are two evolutionary factors that lead to our impression that one species possesses a more drastic or rapid ontogenetic change than its ancestor.

1) Disparate morphology of early stages through selective pressure:

One factor influencing the drastic morphological changes we term metamorphosis is selective pressure on early larval stages. This kind of selection leads evolutionarily to early developmental stages that differ strongly from the adult due to the development of evolutionary novelties, i.e., new structures. These larval structures will usually be reduced in the transition to the adult stage (metamorphosis).

2) Rapid morphological change through condensation:

The other factor is that long, gradual ontogenetic patterns are condensed into a very short phase of the ontogeny and thus appear more drastic, compared to an ancestor with the gradual pattern.

When both factors are coupled, the change from the one phase to the other appears even more drastic.

\section{Selective pressure on early developmental stages}

Since Ernst Haeckel often the idea has been put forward that earlier developmental stages reflect more plesiomorphic conditions than later stages. This implies that earlier stages are more or less "fixed" and are subject to no or only little change during evolution. This idea was also partly coupled to the concept of a so-called phylotypic stage. There are indeed examples where very similar-appearing larvae result in very drastically differing adults (e.g., Høeg \& Møller 2006). Yet, the hypothesis of fixed early stages has been heavily criticized. Already de Beer (1958) presented examples, in which quite the opposite occurs: very strongly differing larvae result in very similar adults. These examples support the view that developmental stages have a certain "selective independence", i.e., that they can evolve independently to a certain degree (Scholtz 2005). The evolutionary plasticity of early developmental stages has been reported in developmental biology (e.g., Damen 2007) and can easily be concluded from simply observing the variety of well-adapted larval forms.

Also to certain non-free living stages the concept of selective independence seems to be applicable. Late embryos of spider, insects and isopods appear very similar in many morphological aspects (one reason for the erection of the phylotypic-stage concept). Yet, all these embryos derived most likely independently from originally larval-developing ancestors, more precisely, from ancestors with an ontogenetic pattern that included an extremely short hatching larva with just four or even three appendage-bearing segments (Waloszek \& Maas 2005). The similarity of all these embryos can, therefore, not be explained by having retained the condition of their common ancestor. Instead, these embryos demonstrate that selective pressures are also present inside an egg, and their similar morphology is obviously an optimal adaptation to such an "environment".

There are only few examples known from the fossil record of arthropods in which earlier developmental stages of more ancestral representatives still lack certain morphological adaptations of (more or less) corresponding stages of modern forms. The larvae of stomatopod crustaceans are one example. Additionally, stomatopod larvae are also interesting for a comparison with the here described fossils, as many stomatopod larvae have a quite comparable morphology to phyllosoma larvae with their extremely thin and enlarged head shields (Fig. 3C). In both types of larvae these structures act as floatation devices. While not all extant stomatopod larvae possess such a type of shield, they all have other floatation devices on the shield, i.e., long spines. At least three of them can be found in all extant stomatopod larvae, a long immobile antero-median rostral spine and two postero-lateral spines (Fig. 3D). Extant adult stomatopods do not possess such spines, and their rostrum is a short and movable plate. The spines are lost and the rostrum is transformed from the moult of the last larval stage to the first juvenile ("post-larva").

Also among fossil stomatopod larvae, which have till now only been found in the Solnhofen Lithographic Limestones, one still to be named form is known to possess such spines (Haug, J.T. et al. 2008). Yet, another form of fossil stomatopod larvae, those of Spinosculda ehrlichi, appears to lack such spines (Fig. 3E, F; Haug, C. et al. 2009b). All specimens found so far must be considered as not well 

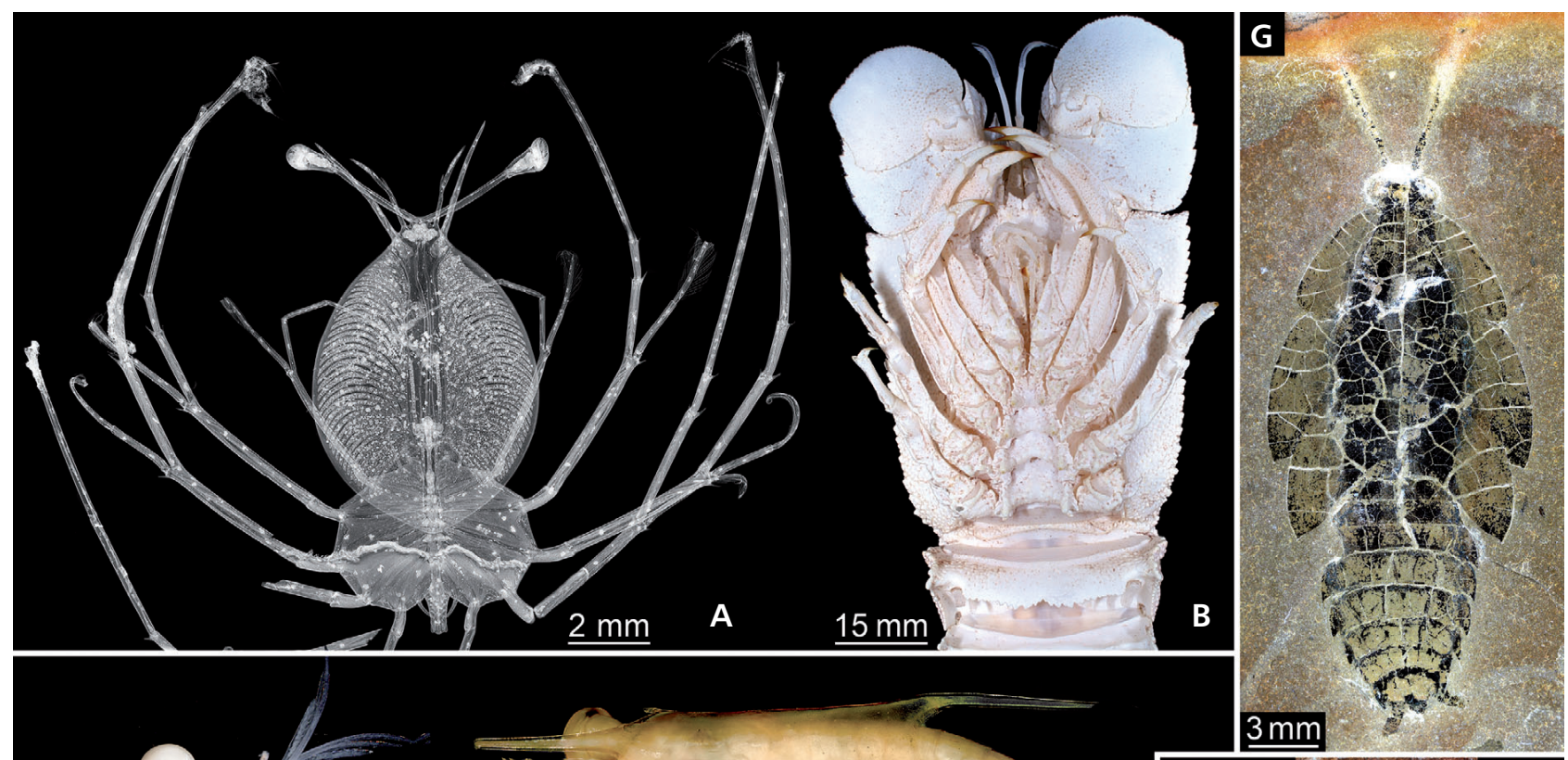

H

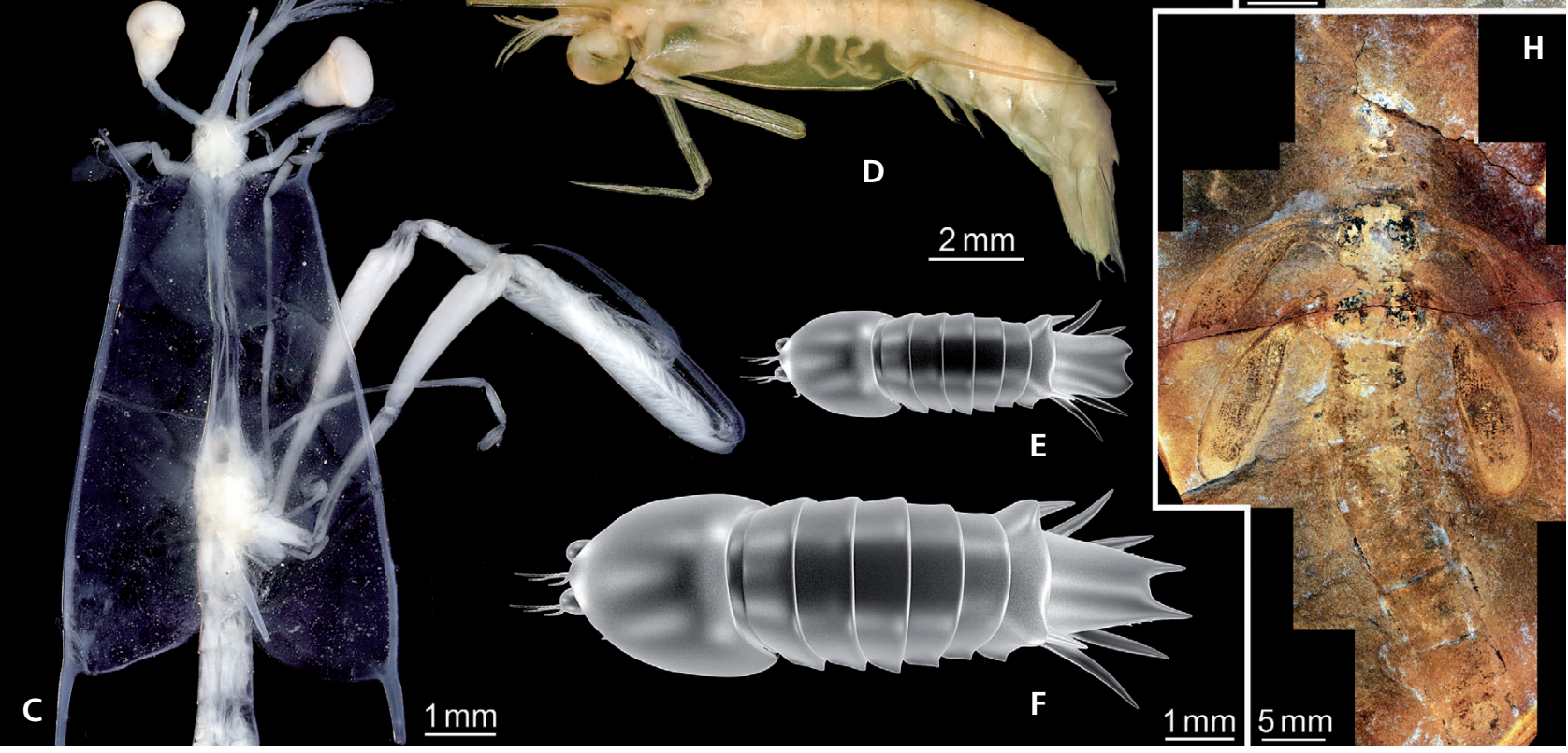

Figure 3. Examples of pre- and post-metamorphic stages in other arthropods. • A - extant phyllosoma larva (YPM IZ 055932). • B - extant adult scyllarid (YPM IZ 035855). - C, D - extant stomatopod larvae; C - supposed alima larva with large, flattened spine-bearing shield and elongate pereiopods (SMF Me5-118KuP); D - supposed erichthus larva with a shield less drastically enlarged, but also with spines (SMF Me5-194Ku); pereiopods thin, but not significantly elongated as in C. $\bullet$ E, F -3 D models of larval stages of the fossil stomatopod Spinosculda ehrlichi Haug, Haug \& Waloszek, 2009 from the Jurassic limestones of Solnhofen, southern Germany; both apparently lack spines on a not-enlarged shield, larval status apparent through developmental state of tail fan; E - earliest known stage, F - last larval stage. $\bullet$ G, $\mathrm{H}$ - insect nymphs from the Carboniferous Mazon Creek Lagerstätte, Illinois, North America; G - blattoid nymph (ROM 47971), H - palaeodictyopteran nymph (ROM 45546); wings developing gradually without metamorphosis.

preserved in the anterior region (Haug, C. et al. 2009b; Haug, J.T. et al. 2010b, 2011; pers. obs.), but one should find at least remains of spines if they had been present, for example, a base of a spine broken off. The absence of even traces of spines was, therefore, interpreted as reflecting the true morphology of the larvae of S. ehrlichi. A juvenile of this species has also been found and, based on the size of the larvae, it most likely represents the first post-larval stage, with the largest known larvae thus representing the last larval stage (Haug, C. et al. 2009b). Therefore, it was at first supposed that this form represents an early megalopa. Yet, in the meantime we got to know also specimens representing an earlier larval stage of $S$. ehrlichi, which also lack spines on the shield (Haug, J.T. et al. 2010b; pers. obs.). This is an 
indication that plesiomorphically spines may have been absent in the larval stages of stomatopods. The presence of such spines on larvae, therefore, represents a novelty, enlarging the morphological gap between the adult and the larva. The selective pressure resulting in the evolution of this novelty is most likely coupled to an adaptation to the planktic life style. The ontogeny of stomatopods with spine-bearing larvae appears therefore "more metamorphic" than the ontogeny of Spinosculda ehrlichi, the latter reflecting the ontogeny of a more basal node within stomatopods.

A second example in which younger instars of more ancestral representatives do not yet possess certain morphological adaptations of earlier stages of modern forms are Carboniferous insects, with nymphal stages that possessed movable wing pads (Fig. 3H). This morphology is generally accepted as an indication of a very gradual developmental pattern reflecting the plesiomorphic type of development for pterygote insects. Extant insect nymphs do not possess such movable wing pads. Kukalová-Peck (1978) suggested that there was significant selective pressure for protective structures for the fragile wings, as nymphs were running on the ground, often slightly inside the soil or at least through obstacles like leaf litter. Evolutionary novelties for wing protection are, for example, the hardened "cases" as seen in cockroach nymphs, which had already evolved in the Carboniferous (Fig. 3G).

These are two examples in which early developmental stages of fossil representatives of a taxon do not yet possess an evolutionary novelty that early developmental stages of later representatives of the taxon have. As pointed out above, the here described fossil specimens could also represent such a case, in which the phyllosoma-like larva had not yet acquired the thin and long appendages of modern phyllosoma larvae.

\section{The condensation of gradual developmental patterns}

There are also examples, in which very gradual ontogenetic patterns are expressed in fossil representatives, while modern relatives have a more condensed pattern. A fossil crustacean for which such a gradual development has been described in very high detail is the Cambrian branchiopod Rehbachiella kinnekullensis Müller, 1983 in spectacular three-dimensional "Orsten"-type preservation (Walossek 1993). The ontogeny of this species has been reconstructed with 30 successive stages from the presumed hatching stage to early juveniles, indicating an even longer sequence until reaching the adult phase. Walossek (1993) used this very gradual pattern as a reference scheme to compare all different eucrustacean developmental patterns with it and identified developmental "jumps" in many lineages. Such jumps are the observable effect of condensation.
Condensation of the nymphal phase of hemimetabolous insects into the pupa stage of holometabolous insects was proposed by Truman \& Riddiford (1999). This is a very plausible scenario for the evolution of metamorphosis in Holometabola, but may still be expanded further by including data from fossil pterygote insects. Also hemimetabolous insects undergo an "incomplete" metamorphosis, i.e., they are "more metamorphic" than their ancestors, for which fossils provided additional clues. As pointed out above, nymphal stages of different lineages acquired wing-protective structures as evolutionary novelties. Yet, additionally certain phases were significantly shortened. Fossil forms appear to have possessed an immature, but fully winged ontogenetic phase. Among extant taxa only mayflies have a single sub-imago stage that is immature, but fully winged. The phase of immature winged instars has, therefore, been condensed to a single stage in mayflies, and to non-existence in all other extant taxa.

The here described phyllosoma-like larvae could also be interpreted as indicating condensation during achelatan evolution. Here the ontogenetic change from the phyllosoma (in the strict sense, i.e., with thin legs) to the post-phyllosoma would occur within at least three moults. This developmental pattern would no longer fulfill the criterion of metamorphosis in arthropods when strictly applied, yet this remains more of a semantic problem.

\section{Conclusions}

Although the presented results must be seen as preliminary, we can highlight the following points:

The here described fossils represent immature stages of an achelatan lobster.

The developmental pattern indicated by these fossils is more gradual than that of any other known achelatan lobster, fossil or extant. This pattern most likely represents the plesiomorphic condition for Achelata.

The pattern also differs in its timing from that of any other developmental pattern within Achelata, with the limbs developing faster than the body (if a phyllosoma in the strict sense was present as earlier instar). Thus, heterochrony, as indicated earlier, plays an important role in achelatan evolution.

Fossil forms are an important source for understanding the evolution of developmental patterns, as these forms can exhibit more plesiomorphic (ancestral) patterns that are no longer expressed in any extant form.

The evolution of metamorphosis is coupled to 1) selective pressure on early developmental stages (morphological disparity) and 2) condensation of ontogenetic pattern (rapidness). Fossil forms can be used to evaluate the evolution of both factors. 


\section{Acknowledgements}

We would like to thank Hermann Polz, Geisenheim, for his inspiring work on the fossil achelatan development and for handing over the two specimens described here to us. Günter Schweigert, Staatliches Museum für Naturkunde Stuttgart, is thanked for helpful discussions and for curating the specimens. We are very grateful to Stefan Liebau, University of Ulm, who made the Axioskop 2 available for us. Many private collectors kindly support us since several years by providing material, for which we would like to thank them heartily (many of them organized in www.solnhofen-fossilienatlas.de). Jean-Bernard Caron, Janet Waddington, and Peter Fenton, all Royal Ontario Museum Toronto, Eric A. Lazo-Wasem, Yale Peabody Museum New Haven, Michael Türkay, Kristin Pietratus, Senckenberg Forschungsinstitut Frankfurt, and Verena Kutschera, University of Ulm, are thanked for kindly providing comparative material and relevant information about it. We are very grateful to Dieter Waloszek, University of Ulm, and his Workgroup Biosystematic Documentation for the possibility to use their facilities and photographic equipment. Very helpful comments to an earlier version of the manuscript were provided by Gengo Tanaka, Gunma Museum of Natural History, Japan, and Donald I. Williamson, Isle of Man, UK. Many people devote their free time to programming freely available software also used in this study, i.e., CombineZM, CombineZP, Microsoft Image Composite Editor, OpenOffice, ImageJ, Gimp, and Blender, for which we are very thankful. JTH was supported by Yale University and the Alexander von Humboldt-Foundation $(\mathrm{AvH})$ with a Feodor Lynen research fellowship for postdoctoral researchers; he is currently funded by AvH with a Feodor Lynen return fellowship. $\mathrm{CH}$ is supported by DAAD with a return fellowship. Finally, we would like to thank our hosts Derek E.G. Briggs, Yale University and Yale Peabody Museum, and Steffen Harzsch, University of Greifswald, for their support.

\section{References}

BAInBRidge, S.P. \& Bownes, M. 1981. Staging the metamorphosis of Drosophila melanogaster. Journal of Embryology and Experimental Morphology 66, 57-80.

Barnes, R.S.K., CAlow, P. \& Olive, P.J.W. 1993. The Invertebrates - a Synthesis. Third Edition. 505 pp. Blackwell Science Ltd., Malden, Oxford, Melbourne, Berlin.

BeER, G.R. de 1958. Embryos and Ancestors. 197 pp. Clarendon Press, Oxford.

Briggs, D.E.G., Sutton, M.D., Siveter, D.J. \& Siveter, D.J. 2005. Metamorphosis in a Silurian barnacle. Proceedings of the Royal Society of London B - Biological Sciences 272, 2365-2369. DOI 10.1098/rspb.2005.3224

DAmEN, W.G.M. 2007. Evolutionary conservation and divergence of the segmentation process in arthropods. Developmental Dynamics 236, 1379-1391. DOI 10.1002/dvdy.21157

Donoghue, M.J., Doyle, J.A., Gauthier, J., Kluge, A.G. \& RowE, T. 1989. The importance of fossils in phylogeny reconstruction. Annual Review of Ecology and Systematics 20, 431-460. DOI 10.1146/annurev.es.20.110189.002243

EdGeCombe, G.D. 2010. Palaeomorphology: fossils and the inference of cladistic relationships. Acta Zoologica 91, 72-80. DOI 10.1111/j.1463-6395.2009.00426.x
Felder, D.L., Martin, J.W. \& Goy, J.W. 1985. Patterns in early postlarval development of decapods, 163-225. In WENNER, A.M. (ed.) Larval Growth. Crustacean Issues 2. Balkema, Rotterdam.

Ferrari, F.D., Fornshell, J., Vagelli, A.A., Ivanenko, V.N. \& DAHMS, H.-U. 2011. Early post-embryonic development of marine chelicerates and crustaceans with a nauplius. Crustaceana 84, 869-893. DOI 10.1163/001121611X579745

Hart, M.W. \& GrosberG, R.K. 2009. Caterpillars did not evolve from onychophorans by hybridogenesis. Proceedings of the National Academy of Sciences of the United States of America 106, 19906-19909.

Haug, C., Haug, J.T., Waloszek, D., Maas, A., Frattigiani, R. \& Liebau, S. 2009a. New methods to document fossils from lithographic limestones of southern Germany and Lebanon. Palaeontologia Electronica 12(3), 6T, 12 pp.

Haug, C., Haug, J.T. \& WaloszeK, D. 2009b. Morphology and ontogeny of the Upper Jurassic mantis shrimp Spinosculda ehrlichi n. gen. n. sp. from southern Germany. Palaeodiversity 2, 111-118.

Haug, J.T., Haug, C. \& Ehrlich, M. 2008. First fossil stomatopod larva (Arthropoda: Crustacea) and a new way of documenting Solnhofen fossils (Upper Jurassic, Southern Germany). Palaeodiversity 1, 103-109.

Haug, J.T., Haug, C., MaAs, A., Kutschera, V. \& Waloszek, D. 2010b. Evolution of mantis shrimps (Stomatopoda, Malacostraca) in the light of new Mesozoic fossils. BMC Evolutionary Biology 10(290), 1-17.

Haug, J.T., Haug, C., Waloszek, D., Maas, A., Wulf, M. \& SChweigert, G. 2009. Development in Mesozoic scyllarids and implications for the evolution of Achelata (Reptantia, Decapoda, Crustacea). Palaeodiversity 2, 97-110.

Haug, J.T., Haug, C., Waloszek, D. \& Schweigert, G. 2011. The importance of lithographic limestones for revealing ontogenies in fossil crustaceans. Swiss Journal of Geosciences, Supplement 1, S85-S98. DOI 10.1007/s00015-010-0033-1

Haug, J.T., MaAs, A. \& WaloszeK, D. 2010a. †Henningsmoenicaris scutula, $\uparrow$ Sandtorpia vestrogothiensis gen. et sp. nov. and heterochronic events in early crustacean evolution. Earth and Environmental Science Transactions of the Royal Society of Edinburgh 100, 311-350. DOI 10.1017/S1755691010008145

Høeg, J.T., Lagersson, N.C. \& Glenner, H. 2004. The complete cypris larva and its significance in thecostracan phylogeny, 197-215. In Scholtz, G. (ed.) Evolutionary Developmental Biology of Crustacea. Crustacean Issues 15, Balkema, Lisse.

HøEG, J.T. \& MøLLER, O.S. 2006. When similar beginnings lead to different ends: Constraints and diversity in cirripede larval development. Invertebrate Reproduction \& Development 49, 125-142. DOI 10.1080/07924259.2006.9652204

Inoue, N., Minami, H. \& Sekiguchi, H. 2004. Distribution of phyllosoma larvae (Crustacea: Decapoda: Palinuridae, Scyllaridae, Synaxidae) in the Western North Pacific. Journal of Oceanography 60, 963-976. DOI $10.1007 / \mathrm{s} 10872-005-0005-7$

JEFFs, A. 2007. Revealing the natural diet of the phyllosoma larvae of spiny lobster. Bulletin of Fisheries Research Agency 20, 9-13.

Johnson, M.W. 1951. A giant phyllosoma larva of a loricate crustacean from the tropical Pacific. Transactions of the American Microscopical Society 70, 274-278. DOI 10.2307/3223060

Kolbasov, G.A., Grygier, M.J., Høeg, J.T. \& Klepal, W. 2008. External morphology of the two cypridiform ascothoracidlarva instars of Dendrogaster: The evolutionary significance 
of the two-step metamorphosis and comparison of lattice organs between larvae and adult males (Crustacea, Thecostraca, Ascothoracida). Zoologischer Anzeiger 247, 159-183. DOI 10.1016/j.jcz.2007.07.007

KukalovÁ-PeCK, J. 1978. Origin and evolution of insect wings and their relation to metamorphosis, as documented by the fossil record. Journal of Morphology 156, 53-126. DOI 10.1002/jmor.1051560104

Kutschera, V., MaAs, A., Waloszek, D., Haug, C. \& Haug, J.T. 2012. Re-study of larval stages of Amphionides reynaudii (Malacostraca: Eucarida) with modern imaging techniques. Journal of Crustacean Biology 32, 916-930.

Marinovic, B., Lemmens, J.W.T.J. \& KnotT, B. 1994. Larval development of Ibacus peronni Leach (Decapoda: Scyllaridae) under laboratory conditions. Journal of Crustacean Biology 14, 80-96. DOI 10.2307/1549057

Meigen, J.W. 1830. Systematische Beschreibung der bekannten europäischen zweiflügeligen Insekten. Volume 6. 401 pp. +12 pl. Schulzische Buchhandlung, Hamm.

Mikami, S. \& Greenwood, J.G. 1997. Complete development and comparative morphology of larval Thenus orientalis and Thenus sp. (Decapoda: Scyllaridae) reared in the laboratory. Journal of Crustacean Biology 17, 289-308. DOI 10.2307/1549280

MüLLER, K.J. 1983. Crustacea with preserved soft parts from the Upper Cambrian of Sweden. Lethaia 16, 93-109. DOI 10.1111/j.1502-3931.1983.tb01704.x

MüLLER, O.F. 1776. Zoologiae Danicae prodromus, seu Animalium Daniae et Norvegiae indigenarum characteres, nomina, et synonyma imprimis popularium. 322 pp. Havniae, typis Hallageriis.

Münster, G. Graf Zu 1839. Decapoda Macroura. Abbildung und Beschreibung der fossilen langschwänzigen Krebse in den Kalkschiefern von Bayern mit XXX nach der Natur gezeichneten Tafeln. Beiträge zur Petrefaktenkunde 2, 1-88.

OlESEN, J. 2005. Larval development of Lynceus brachyurus (Crustacea, Branchiopoda, Laevicaudata): redescription of unusual crustacean nauplii, with special attention to the molt between last nauplius and first juvenile. Journal of Morphology 264, 131-148. DOI 10.1002/jmor. 10202

Pasini, G. \& Garassino, A. 2009. A new phyllosoma form (Decapoda, ?Palinuridae) from the Late Cretaceous (Cenomanian) of Lebanon. Atti della Società Italiana di Scienze naturali e del Museo civico di Storia naturale in Milano 150(1), 21-28.

PeChenik, J.A. 2006. Larval experience and latent effects - metamorphosis is not a new beginning. Integrative \& Comparative Biology 46, 323-333. DOI 10.1093/icb/icj028

Polz, H. 1972. Entwicklungsstadien bei fossilen Phyllosomen (Form A) aus den Solnhofener Plattenkalken. Neues Jahrbuch für Geologie und Paläontologie, Monatshefte 11, 678-689.

Polz, H. 1973. Entwicklungsstadien bei fossilen Phyllosomen (Form B) aus den Solnhofener Plattenkalken. Neues Jahrbuch für Geologie und Paläontologie, Monatshefte 5, 284-296.

Polz, H. 1984. Krebslarven aus den Solnhofener Plattenkalken. Archaeopteryx 2, 30-40.

Polz, H. 1995. Ein außergewöhnliches Jugendstadium eines palinuriden Krebses aus den Solnhofener Plattenkalken. Archaeopteryx 13, 67-74.

Polz, H. 1996. Eine Form-C-Krebslarve mit erhaltenem Kopfschild (Crustacea, Decapoda, Palinuroidea) aus den Solnhofener Plattenkalken. Archaeopteryx 14, 43-50.

Rowe, L. \& Ludwig, D. 1991. Size and timing of metamorphosis in complex life cycles: time constraints and variation. Ecology 72, 413-427. DOI 10.2307/2937184
Rust, J. 2006. Die Bedeutung von Fossilien für phylogenetische Rekonstruktionen. Species, Phylogeny and Evolution 1, 73-87.

Saunders, M.I, Thompson, P.A., Jeffs, A.G., Säwström, C., Sachlikidis, N., Beckley, L.E. \& Waite, A.M. 2012. Fussy feeders: phyllosoma larvae of the Western Rocklobster (Panulirus cygnus) demonstrate prey preference. PLOS ONE 7, e36580. DOI 10.1371/journal.pone.0036580

Scholtz, G. 2005. Homology and ontogeny: Pattern and process in comparative developmental biology. Theory in Biosciences 124, 121-143.

Stimpson, W. 1866. Descriptions of new genera and species of macrurous Crustacea from the coasts of North America. Proceedings of the Chicago Academy of Sciences 1, 46-48.

Tanaka, G., Smith, R.J., Siveter, D.J. \& Parker, A.R. 2009. Threedimensionally preserved decapod larval compound eyes from the Cretaceous Santana formation of Brazil. Zoological Science 26, 846-850. DOI 10.2108/zsj.26.846

Truman, J.W. \& Riddiford, L.M. 1999. The origins of insect metamorphosis. Nature 401, 447-452.

Walossek, D. 1993. The Upper Cambrian Rehbachiella and the phylogeny of Branchiopoda and Crustacea. Fossils \& Strata $32,1-202$.

Walossek, D., Høeg, J.T. \& Shirley, T.C. 1996. Larval development of the rhizocephalan cirripede Briarosaccus tenellus (Maxillopoda: Thecostraca) reared in the laboratory: a scanning electron microscopy study. Hydrobiologia 328, 9-47. DOI 10.1007/BF00016898

Waloszek, D. 2003. Cambrian 'Orsten'-type preserved arthropods and the phylogeny of Crustacea, 69-87. In LEGAKIS, A., Sfenthourakis, S., Polymeni, R. \& Thessalou-Legaki, M. (eds) The New Panorama of Animal Evolution. Proceedings of the $18^{\text {th }}$ International Congress on Zoology.

WaloszeK, D. \& MAas, A. 2005. The evolutionary history of crustacean segmentation: a fossil-based perspective. Evolution \& Development 7, 515-527. DOI 10.1111/j.1525-142X.2005.05056.x

Webier, W.R. \& Bоотн, J.D. 2001. Larval stages, developmental ecology, and distribution of Scyllarus sp. Z (probably Scyllarus aoteanus Powell, 1949) (Decapoda: Scyllaridae). New Zealand Journal of Marine and Freshwater Research 35, 1025-1056. DOI 10.1080/00288330.2001.9517061

Williamson, D.I. 1969. Names of larvae in the Decapoda and Euphausiacea. Crustaceana 16, 210-213. DOI 10.1163/156854069X00510

Williamson, D.I. 1982. Larval morphology and diversity, 43-110. In ABele, L.G. (ed.) The Biology of Crustacea 2. Embryology, Morphology and Genetics. Academic Press, New York, London.

Williamson, D.I. 1988. Incongruous larvae and the origin of some invertebrate lifehistories. Progress in Oceanography 19, 87-116. DOI 10.1016/0079-6611(87)90005-X

WiLLIAMSON, D.I. 2006. Hybridization in the evolution of animal form and life-cycle. Zoological Journal of the Linnean Society 148, 585-602. DOI 10.1111/j.1096-3642.2006.00236.x

Williamson, D.I. 2009. Caterpillars evolved from onychophorans by hybridogenesis. Proceedings of the National Academy of Sciences of the United States of America 106, 19901-19905.

Williamson, D.I. 2012. The origins of chordate larvae. Cell \& Developmental Biology 1, 101.

WiLLIS, J.H. \& CoX-FosteR, D.L. 2010. Insect metamorphosis via hybridogenesis: An evidentiary rebuttal. Journal of Insect Physiology 56, 333-335. DOI 10.1016/j.jinsphys.2009.11.007 